\title{
Краевая и дефектная люминесценция мощных InGaN/GaN ультрафиолетовых светоизлучающих диодов
}

\author{
(C) В.Т. Шамирзаев ${ }^{\times}$, В.А. Гайслер*х, Т.С. Шамирзаев*+ \\ × Новосибирский государственный технический университет, \\ 630073 Новосибирск, Россия \\ * Институт фризики полупроводников им. А.В. Ржанова \\ Сибирского отделения Российской академии наук, \\ 630090 Новосибирск, Россия \\ + Уральский федеральный университет, \\ 620002 Екатеринбург, Россия \\ E-mail: tim@isp.nsc.ru
}

(Получена 27 апреля 2016 г. Принята к печати 10 мая 2016 г.)

\begin{abstract}
Приведены результаты исследования спектрального состава излучения ультрафиолетовых $\mathrm{InGaN} / \mathrm{GaN}$ светоизлучающих диодов и его зависимости от текущего через структуру тока. Интенсивность ультрафиолетового вклада в интегральную люминесценцию диода монотонно возрастает с ростом плотности текущего через структуру тока, несмотря на падение квантовой эффективности излучения. Установлены условия возбуждения электролюминесценции, позволяющие увеличить долю ультрафиолетового излучения до 97\%. Показано, что неоднородная генерация протяженных дефектов, пронизывающих активную область светодиодов в процессе деградации структур при локальном токовом перегреве уменьшает интегральную интенсивность излучения, но не оказывает влияния на относительную интенсивность излучения диода в ультрафиолетовой $(370$ нм) и видимой $(550$ нм) областях спектра.
\end{abstract}

\section{1. Введение}

Появление мощных светоизлучающих (СИД) и лазерных диодов ультрафиолетового диапазона на основе широкозонных полупроводников соединений нитридов In, Ga и Al открывает новые возможности для развития люминесцентных методов анализа. Доступность $\mathrm{AlGaN} / \mathrm{InGaN} / \mathrm{GaN}$ СИД с длиной волны излучения 365-375 нм и мощностью излучения до 120 мВт [1] делает такие приборы перспективными источниками возбуждения люминесценции в широком классе органических и неорганических материалов и структур.

К сожалению, отсутствие подложек, согласованных по постоянной решетки с $\mathrm{GaN}$ и его твердыми растворами, приводит к формированию в структурах для СИД высокой плотности дислокаций и заметной концентрации точечных дефектов [2,3]. Несмотря на высокую плотность дислокаций, светодиоды на основе $\mathrm{GaN}$ демонстрируют высокую эффективность излучения. Для ее объяснения были предложены механизмы, объясняющие подавление латеральной диффузии носителей заряда к дефектам и дислокациям, содержащим центры безызлучательной рекомбинации, такие так: 1) локализация экситонов на неоднородных флуктуациях потенциала, вызванных флуктуациями состава или разделением фаз в слое InGaN [4], а также дефектами кристаллической структуры, которые приводят к образованию хвостов плотности состояний в активной области светодиода; 2) встроенное пьезоэлектрическое поле, направленное против поля области пространственного заряда [5]. Тем не менее наличие дефектов и дислокаций приводит и к негативным последствиям. Возбуждение дефектов текущим через структуру электрических током и собственным ультрафиолетовым излучением приводит к появлению люминесценции в видимом спектральном диапазоне [6]. При использовании СИД в качестве источников возбуждения люминесценции это ,паразитное“ излучение создает проблемы, складываясь с фотолюминесценцией материалов и структур, излучающих в том же спектральном диапазоне.

В данной работе изучалось влияние условий возбуждения электролюминесценции на спектральный состав излучения мощных коммерческих ультрафиолетовых (длина волны максимума излучения, заявленная производителем 365-370 нм) светоизлучающих диодов фирмы Cree, построенных на основе гетероструктур $p$-AlGaN/InGaN/n-GaN. Показано, что выбор условий возбуждения позволяет заметно уменьшить долю „паразитного“ видимого излучения.

\section{2. Детали эксперимента}

Спектры электролюминесценции измерялись на установке, построенной на основе спектрометра Acton Advanced SP2500A, оснащенного охлаждаемой жидким азотом ПЗС-камерой Spec-10 System c повышенной чувствительность в ультрафиолетовой области спектра. Для возбуждения электролюминесценции светоизлучающих диодов использовался генератор тока. При низких токах $(I<0.05 \mathrm{~A})$ в качестве генератора тока использовался характериограф TR-4805 (производства фирмы $\mathrm{EMG}$, Венгрия), позволяющий управлять величинами поданных на структуру тока и напряжения с точностью 2 нА и $0.1 \mathrm{MB}$ соответственно. Мощность излучения СИД измерялась измерителем оптической мощности PM100USB фирмы Thorlabs в условиях прямого контакта СИД с фотодиодным сенсором [7]. 


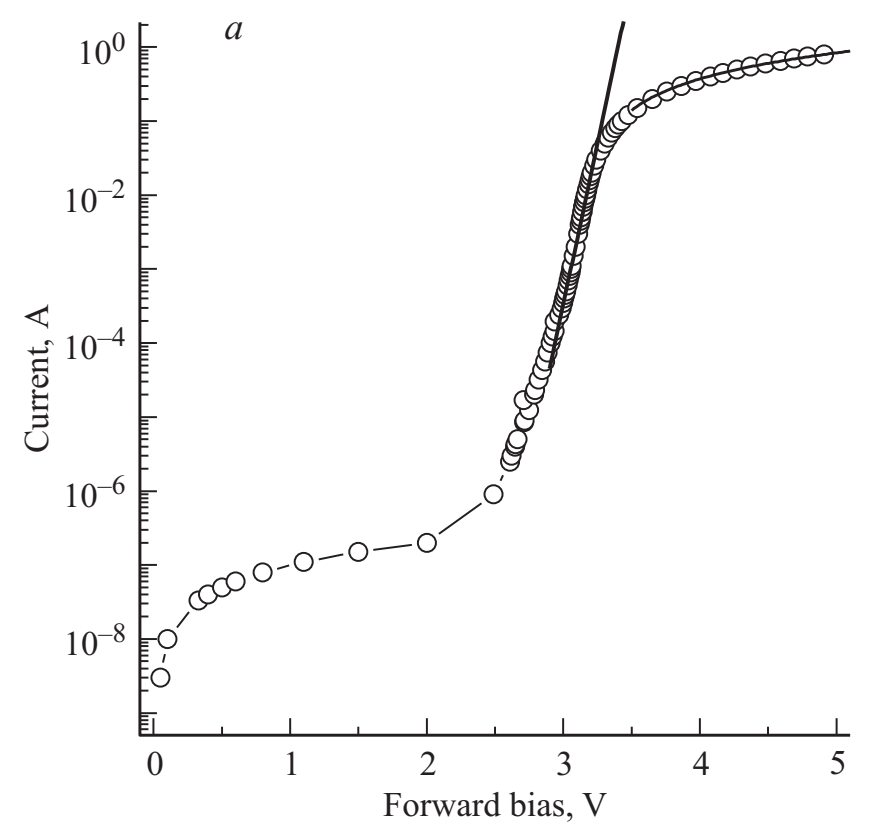

ния $(U)$ представлена на рис. $1, a$. В области малых напряжений и токов $\left(I<5 \cdot 10^{-8} \mathrm{~A}\right)$ наблюдается участок экспоненциального роста тока $(0<U<0.4 \mathrm{~B})$, переходящий в насыщение при напряжениях $0.5<U<2.0 \mathrm{~B}$, обусловленный рекомбинацией текущих через гетероструктуру носителей заряда на дефектных состояниях в области пространственного заряда $p-n$-перехода [8]. Повышение напряжения $U>2.0$ В приводит к экспоненциальному возрастанию тока

$$
I \propto \exp \left(\frac{e U}{n_{j} k T}\right),
$$

где $k T$ - тепловая энергия, $e-$ элементарный заряд, а $n_{j}$ - фактор идеальности.

В диапазоне напряжений $2.1<U<3.0$ В (и токов $\left.10^{-6}<I<10^{-3} \mathrm{~A}\right)$ фактор идеальности монотонно уменьшается от 4 до 2 и сохраняет значение 2 для напряжений $3.0<U<3.3 \mathrm{~B}$. При $U>3.4 \mathrm{~B}$ зависимость тока от напряжения становится линейной. Линейность этого участка ВАХ обусловлена последовательным сопротивлением светодиода и измерительного тракта. Сопротивление цепи измерительного тракта нашей системы не превышало 150 мОм, следовательно, определенное по наклону ВАХ сопротивление 2.1 Ом связано с протеканием тока в СИД. Зависимость мощности интегрального излучения СИД от тока при прямом смещении показана на рис. $1, b$. Пороговый ток $\left(I_{p}\right)$, при котором регистрировалось излучение света мощностью 25 пВт, был равен 0.8 мкА. На характеристике можно выделить три характерных участка: квадратичное возрастание мощности излучения от 25 пВт до $0.2 \mathrm{MBT}$ на первом участке $I<1 \mathrm{мA}$, плавно переходит в линейную зависимость в диапазоне токов $1<I<200$ мА и, наконец, при $I>200$ мА ватт-амперная характеристика становится сублинейной и выходит на насыщение.

Спектры электролюминесценции СИД в зависимости от текущего через структуру тока, измеренные при $T=300 \mathrm{~K}$, приведены на рис. 2, a. В спектрах наблюдается две полосы: относительно узкая (ширина на половинной интенсивности 60 мэВ) полоса ультрафиолетового излучения с положением максимума $369 \mathrm{Hм}$, обозначенная на рисунке как $U F$, и широкая „дефектная“ полоса, обозначенная на рисунке как $D$, обусловленная рекомбинацией носителей заряда через состояния дефектов в области InGaN квантовой ямы, встроенной в $p-n$ переход структуры [9]. Положение максимума полосы $D$ и ее ширина сильно зависят от текущего через структуру тока. При токе $I=1.5$ мкА положение максимума полосы $D$ равно 600 нм, а ширина на половинной интенсивности 600 мэВ. Повышение тока до $I=0.3$ А приводит к монотонному смещению полосы в высокоэнергетическую область спектра до 560 нм и уменьшению ее ширины до 400 мэВ. При низких токах возбуждения, соответствующих сверхлинейному участку ватт-амперной характеристики, полоса $D$ доминирует в спектрах ЭЛ, и ее интегральная интенсивность превышает интенсивность полосы $U F$. Повышение тока приводит к перераспределению интенсивности излучения между полосами, 


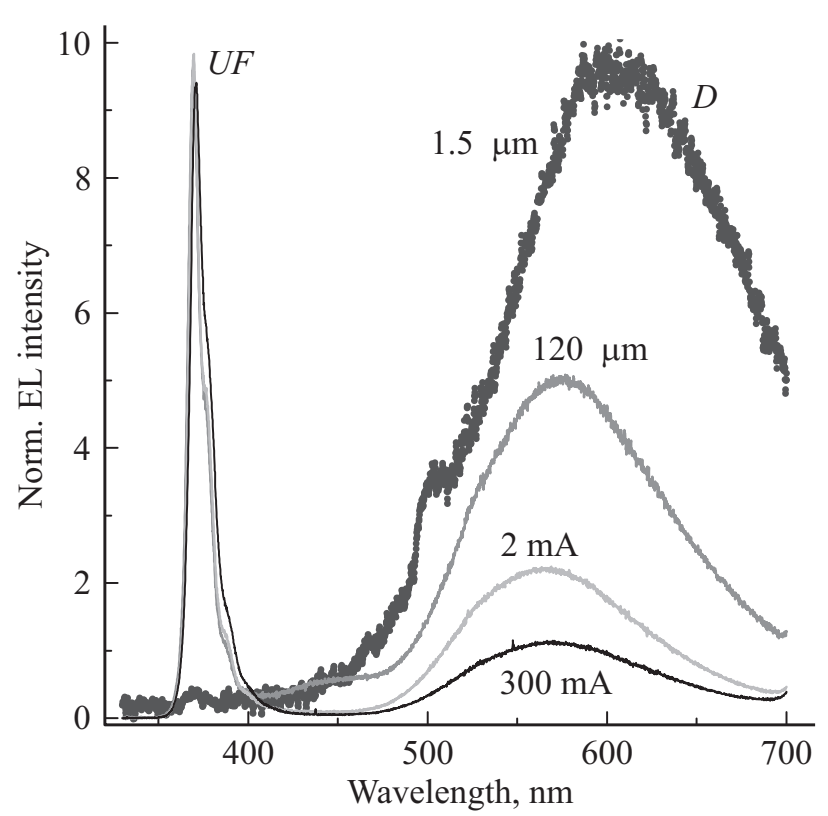

Рис. 2. Спектры электролюминесценции СИД, измеренные при комнатной температуре при различных токах, текущих через структуру.

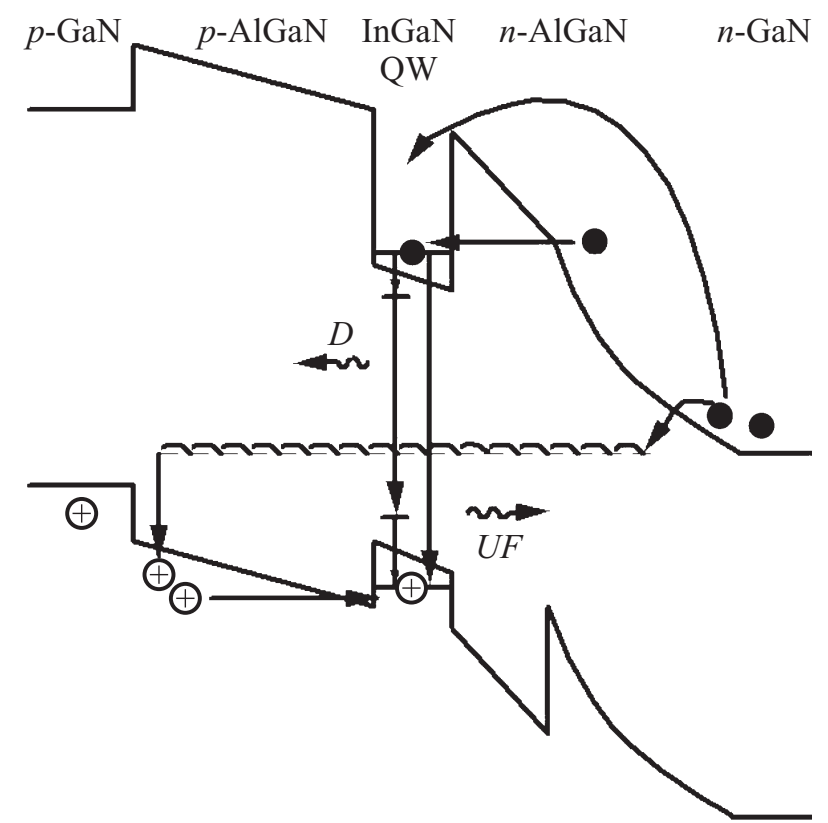

Рис. 3. Зонная диаграмма светоизлучающей гетероструктры.

видно, что относительная интенсивность полосы $U F$ возрастает. Анализ полученных экспериментальных данных позволяет определить механизмы протекания тока и, следовательно, понять условия возбуждения различных спектральных компонент электролюминесценции СИД. В области малых токов $(I<0.8$ мкА $)$ и напряжений $(U<2$ В) ВАХ демонстрирует экспоненциальное возрастание тока с ростом напряжения, переходящее в насыщение. Такое поведение ВАХ свидетельствует о туннельном протекании тока через состояния дефектов с глубокими уровнями, как это схематически показано на зонной диаграмме, приведенной на рис. 3. Высокая плотность дислокаций и формирование столбчатой структуры пленок $\mathrm{GaN}$ и $\mathrm{InGaN}$ на не согласованных по параметру решетки подложках $[10,11]$ позволяет сделать вывод о том, что дефекты, через которые протекает ток при низких напряжениях $(U<2$ В), являются протяженными и насквозь пронизывают активную область светодиодов [12]. Отсутствие электролюминесценции при токах, соответствующих этой области ВАХ, указывает на безызлучательный характер рекомбинации носителей заряда через уровни таких дефектов.

C ростом тока при $I>0.8$ мкА структура начинает излучать, что указывает на появление дополнительного канала протекания тока. Положение максимума полосы излучения $D$ и ее ширина свидетельствуют о том, что излучательная рекомбинация текущих по этому, дополнительному каналу носителей заряда идет через набор дефектов с распределением состояний в области $p-n$-перехода. Высокоэнергетический сдвиг и уменьшение ширины полосы с ростом тока (и, следовательно, ростом концентрации носителей заряда, заполняющих эти дефекты) указывают на то, что плотность дефектных состояний уменьшается с увеличением энергии локализации носителей на этих состояниях. Таким образом, в области $p-n$-перехода СИД имеет место хвост плотности дефектных состояний, типичный для разупорядоченных систем [13]. Квадратичная зависимость мощности излучения на ватт-амперной характеристике в диапазоне токов $10^{-6}<I<10^{-3}$ А сопровождается сильным изменением фактора идеальности на ВАХ. Перечисленные факты, а также литературные данные [14-16] указывают на то, что в этом диапазоне токов заполнение дефектных состояний, ответственных за появление полосы $D$, идет главным образом за счет туннеллирования носителей заряда. Переход от квадратичной зависимости ваттамперной характеристики к линейной при дальнейшем повышении тока $\left(I>10^{-3} \mathrm{~A}\right)$ в совокупности с описываемой формулой

$$
I \propto \exp \left(\frac{e U}{2 k T}\right)
$$

BAX показывает на изменение механизма протекания тока через структуру от туннелирования к инжекции. Сублинейность ватт-амперной характеристики при высоких уровнях инжекции обусловлена падением квантовой эффективности излучения СИД за счет появлением дополнительных каналов безызлучательной рекомбинации $[17,18]$.

Зависимость вклада УФ излучения в электролюминесценцию СИД от текущего через структуру тока показана на рис. 4, $a$. Доля УФ излучения возрастает с повышением тока при переходе к режиму эффективной инжекции носителей заряда в область встроенной в $p-n$ переход InGaN квантовой ямы. При токах выше $0.05 \mathrm{~A}$ уже половина излучения идет через УФ канал, а при токе 0.3 А ультрафиолетовая компонента излучения достигает $83 \%$ от интегральной интенсивности свечения СИД. К сожалению, дальнейшее повышение текущего 

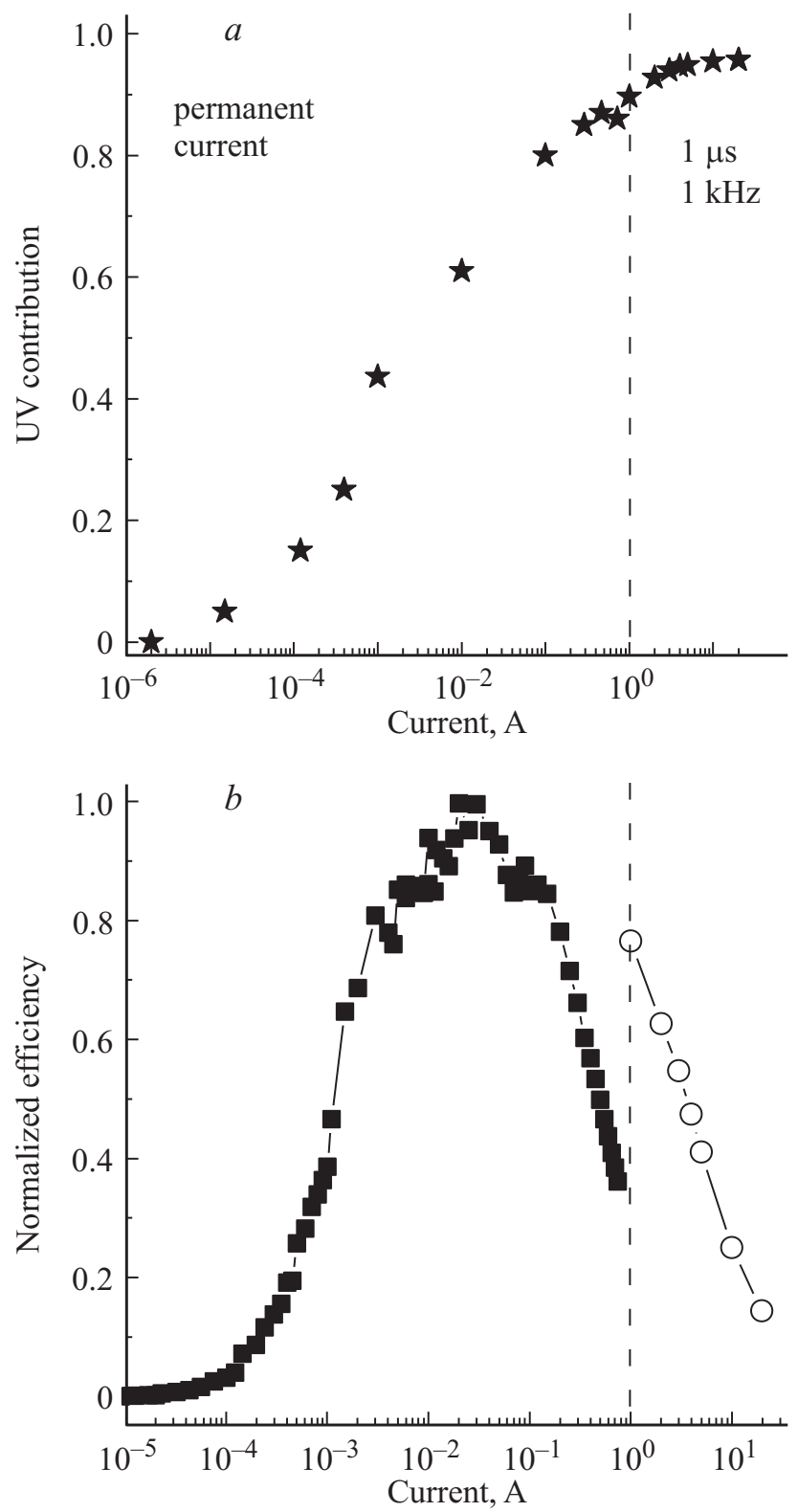

Рис. 4. $a$ - доля УФ излучения в электролюминесценции СИД в зависимости от прямого тока. $b-$ нормированная на максимальное значение квантовая эффективность излучения СИД. Максимальное значение соответствует эффективности $6 \%$. Слева от вертикальной линии - режим непрерывного возбуждения, справа - возбуждения импульсами тока (длительность импульса 1 мкс, частота повторения 1 кГц).

через структуру тока почти не приводит к росту доли УФ излучения. В области сублинейности ватт-амперной характеристики от 0.3 до 0.7 А доля УФ излучения практически не зависит от тока.

Насыщение доли УФ излучения в области сублинейности ватт-амперной характеристики могло бы быть связано с падением квантовой эффективности излучения СИД в ультрафиолетовом диапазоне при высоких уровнях инжекции. Необходимо, однако, отметить, что мы не наблюдаем прямой зависимости между квантовой эф- фективностью излучения СИД и долей УФ компоненты в спектрах его электролюминесценции. Действительно, максимальная квантовая эффективность СИД $\eta$ (равна $\sim 6 \%)$, определенная в соответствии с предложенным в работе [19] выражением

$$
\eta=\frac{P e}{\hbar \omega I}
$$

где $P$ - мощность сигнала, а $\hbar \omega-$ энергия излучения, имеет место при токе 0.03 А как это видно на рис. $4, b$. Таким образом, падение квантовой эффективности излучения при изменении тока от 0.03 до $0.3 \mathrm{~A}$ сопровождается ростом вклада УФ компоненты в интегральное излучение СИД.

Другим механизмом, обеспечивающим повышение относительной доли УФ компоненты излучения СИД с ростом тока, могло бы быть насыщение канала излучательной рекомбинации через уровни дефектов в активной области светодиода. Если это предположение верно, то для уменьшения относительной интенсивности видимой компоненты излучения СИД необходимо увеличивать концентрацию носителей заряда в активной области прибора. В режиме протекания постоянного тока максимальная концентрация электронов и дырок в области $p-n$-перехода ограничена тепловыделением. Поскольку температура СИД определяется электрической мощностью, выделяемой на диоде, переход в импульсный режим возбуждения позволяет уменьшить температуру кристалла при повышении тока (и, следовательно, концентрации носителей заряда в активной области СИД), протекающего через диод [20].

Переход к импульсному возбуждению действительно позволил нам повысить относительную УФ компоненту излучения СИД. Как это видно на рис. 4, $a$, в правой части которого приведены результаты измерения для частоты повторения 1 кГц и длительности импульса 1 мкс, доля УФ изучения СИД монотонно растет с повышением силы тока и достигает 97.5 $( \pm 0,5) \%$ при возбуждении импульсами тока $20 \mathrm{~A}$ (что соответствует средней мощности, выделяемой на диоде 0.2 Вт). При длительности импульса 1 мкс и фиксированном токе (в диапазоне токов от 1 до $20 \mathrm{~A}$ ) относительная интенсивность полос в спектрах электролюминесценции не зависела от частоты повторения в пределах $0.1-10$ кГц.

Отметим, что уменьшение температуры кристалла при импульсном возбуждении приводило к росту квантовой эффективности излучения, аналогично тому, как это было показано в работе [16].

На рис. $4, b$ видно, что переход от постоянного тока к импульсному (для частот $0.1-10$ кГц и длительности импульса 1 мкс) при фиксированной силе текущего через структуру тока 1 А приводит к возрастанию квантовой эффективности в 2.5 раза. Однако дальнейший рост силы импульсного тока приводит к падению квантовой эффективности. Абсолютное значение квантовой эффективности при импульсном токе 20 А не превышает $1 \%$, следовательно, основным механизмом возрастания вклада УФ компоненты излучения является насыщение дефектного канала рекомбинации в активной области СИД. 

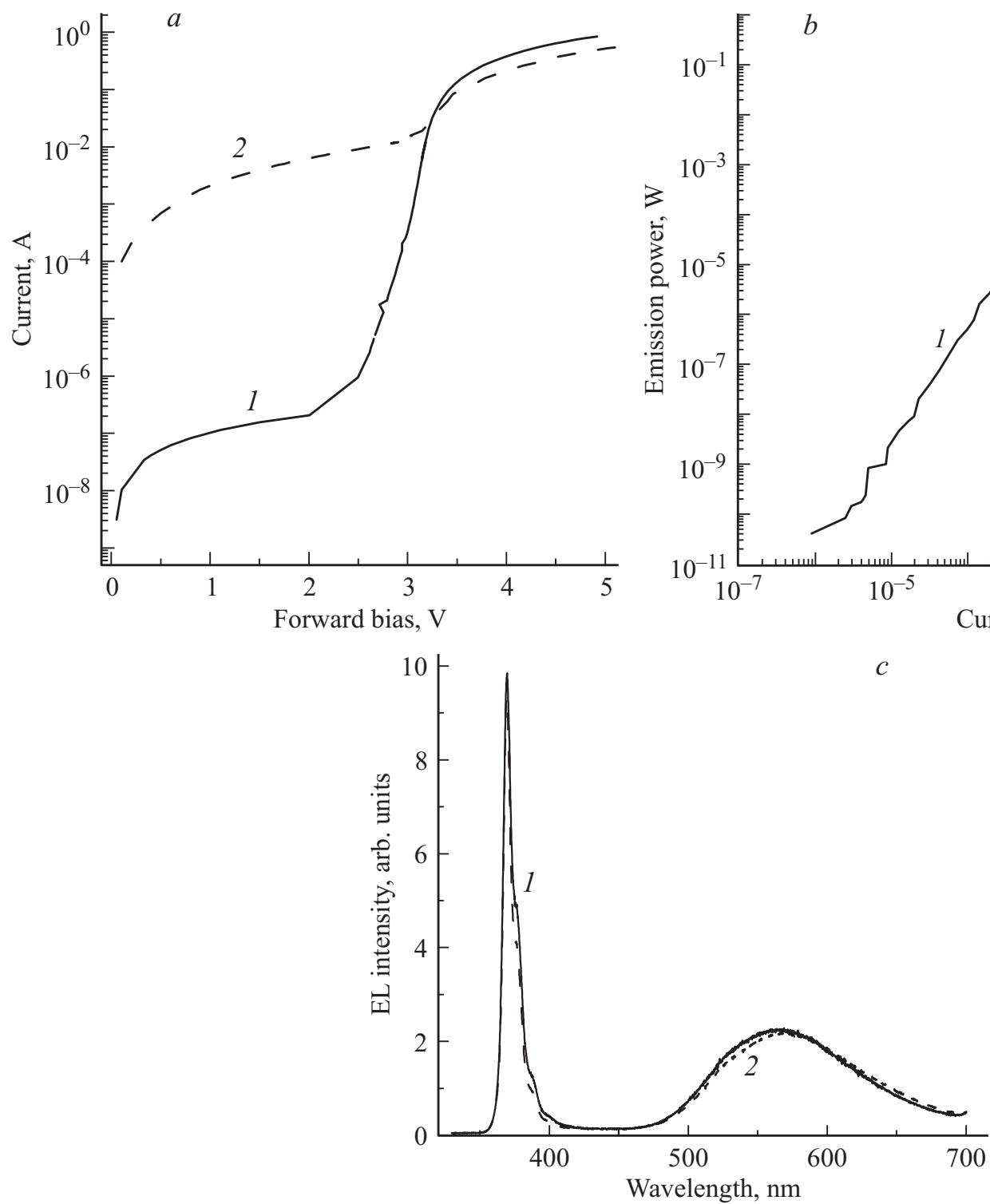

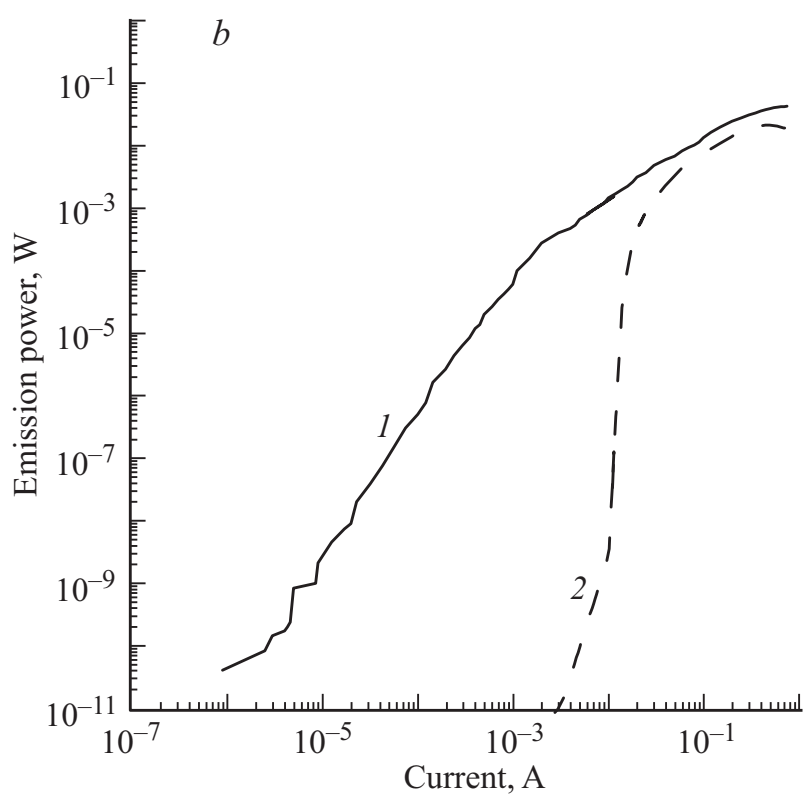

Wavelength, nm

Рис. 5. Вольт-амперные $(a)$ и ватт-амперные $(b)$ характеристики исходных $(1)$ и деградировавших $(2)$ светоизлучающих диодных структур. $c$ - спектры электролюминесценции исходных (1) и деградировавших (2) светоизлучающих диодных структур, измеренные при прямом токе $15 \mathrm{MA}$.

Попытки повышения концентрации носителей заряда в области встроенной в $p-n$-переход InGaN квантовой ямы за счет увеличения силы текущего через структуру тока до 1.3 А при постоянном возбуждении и до $10 \mathrm{~A}$ при импульсном возбуждении с длительностью импульca 10 мкс (при частотах повторения $0.1-10$ кГц) приводили к деградации параметров СИД, что проявлялось в уменьшении интенсивности электролюминесценции. В импульсном режиме возбуждения деградация начиналась при средней мощности, выделяемой на гетероструктуре, не превышающей 1 Вт. Следовательно, можно делать вывод о локальном перегреве гетероструктуры в таком режиме возбуждения [12].

Вольт-амперные и ватт-амперные характеристики исходных и деградировавших диодных структур показаны на рис. $5, a$ и $b$ соответственно. По изменению формы
BAX хорошо видно, что протекающий через дефекты ток увеличивается после деградации на 4 порядка величины, что соответствует литературным данным [12]. Одновременно на 4 порядка величины от $10^{-6}$ до $10^{-2} \mathrm{~A}$ возрастает пороговый ток, при котором появляется электролюминесценция СИД. Для оценки влияния деградации СИД на концентрацию дефектов, являющихся центрами излучательной рекомбинации, в окрестности встроенной в $p-n$-переход InGaN квантовой ямы мы провели сравнение спектров ЭЛ измеренных до и после деградации структур. Спектры, измеренные при малом токе 15 мА, когда относительный вклад ,дефектной люминесценции“ достаточно высок, показаны на рис. $5, b$. Видно, что относительная интенсивность полос $U F$ и $D$ в спектрах электролюминесценции СИД после деградации не изменяется. Следовательно, образование 
протяженных дефектных токовых каналов не приводит к генерации дополнительных дефектов - центров излучательной рекомбинации в активной области структур. Таким образом, деградация проявляется в образовании дополнительных дефектных проводящих каналов, шунтирующих ток носителей заряда в активную область СИД, что приводит к падению интегральной интенсивности излучения СИД при токах $0.1-0.7 \mathrm{~A}$, соответствующих инжекционному механизму возбуждения ЭЛ, в 2.5 раза. Полученные нами результаты хорошо согласуются с литературными данными о том, что генерация дефектов есть следствие неоднородного по площади структуры локального перегрева, имеющего место при шнуровании тока в СИД [12,21].

\section{4. Заключение}

В работе изучены электрофизические и спектральные характеристики мощных ультрафиолетовых (365 нм) светоизлучающих диодов построенных на основе гетероструктур $p$-AlGaN/InGaN/n-GaN. Показано, что доля ультрафиолетового вклада в интегральную люминесценцию диода монотонно возрастает с ростом плотности текущего через структуру тока, за счет насыщения дефектного канала рекомбинации в активной области СИД. При возбуждении светоизлучающих диодов постоянным током 0.7 А (указанным производителем как максимально допустимый) доля УФ компоненты излучения СИД не превышает 83\%. Переход в режим импульсного возбуждения (ток 20 А, длительность импульса 1 мкс, при частоте повторения 1 кГц) позволяет увеличить долю УФ компоненты излучения до 97\%. Деградация диодов при локальном перегреве структуры за счет образования пронизывающих активную область СИД протяженных дефектов не приводит к генерации дополнительных дефектов - центров излучательной рекомбинации в активной области структур.

Работа выполнена при финансовой поддержке (постановление № 211) правительства Российской Федерации, контракт № 02.А03.21.0006, РФФИ (проект № 14-0200033).

\section{Список литературы}

[1] А. Туркин. Полупроводниковая светотехника 3, 38 (2015).

[2] A. Mogilatenko, V. Kueller, A. Knauer, J. Jeschke, U. Zeimer, M. Weyers, G. Tränkle. J. Cryst. Growth, 402, 222 (2014).

[3] T. Lang, M.A. Odnoblyudov, V.E. Bougrov, S. Suihkonen, O. Svensk, P.T. Törmä, M. Sopanen, H. Lipsanen. J. Cryst. Growth, 298, 276 (2007).

[4] P. Fischer, J. Christen, S. Nakamura. Jpn. J. Appl. Phys., 39, L129 (2000).

[5] T. Takeuchi, S. Sota, M. Katsuragawa, M. Komori, H. Takeuchi, H. Amano, I. Akasaki. Jpn. J. Appl. Phys., Pt 2, 36, L382 (1997).

[6] P.P. Paskov, R. Schifano, T. Paskova, T. Malinauskas, J.P. Bergman, B. Monemar, S. Figge, D. Hommel. Physica B, 376-377, 473 (2006).
[7] N.G. Galkin, E.A. Chusovitin, D.L. Goroshko, A.V. Shevlyagin, A.A. Saranin, T.S. Shamirzaev, K.S. Zhuravlev, A.V. Latyshev. Appl. Phys. Lett., 101, 163501 (2012).

[8] С.В. Булярский, Н.С. Грушко, А.И. Сомов, А.В. Лакалин. ФТП, 31, 1146 (1997).

[9] В.Е. Кудряшов, К.Г. Золин, А.Н. Туркин, А.Э. Юнович, А.Н. Ковалев, Ф.И. Маняхин. ФТП, 31, 1304 (1997).

[10] Z. Zhong, O. Ambacher, A. Link, V. Holy, J. Stangl, R.T. Lechner, T. Roch, G. Bauer. Appl. Phys. Lett., 80, 3521 (2002).

[11] Р.Н. Кютт, Г.Н. Мосина, М.П. Щеглов, Л.М. Сорокин. ФТТ, 48, 1491 (2006).

[12] А.Л. Закгейм, М.Е. Левинштейн, В.П. Петров, А.Е. Черняков, Е.И. Шабунина, Н.М. Шмидт. ФТП, 46, 219 (2012).

[13] Б.И. Шкловский, А.А. Эфрос. Электронные свойства легированных полупроводников (М., Наука, 1979) с. 416.

[14] D. Yan, H. Lu, D. Chen, R. Zhang, Y. Zheng. Appl. Phys. Lett., 96, 083504 (2010).

[15] В.Е. Кудряшов, С.С. Мамакин, А.Н. Туркин, А.Э. Юнович, А.Н. Ковалев, Ф.И. Маняхин. ФТП, 35, 861 (2001).

[16] И.А. Прудаев, И.Ю. Голыгин, С.Б. Ширапов, И.С. Романов, С.С. Хлудков, О.П. Толбанов. ФТП, 47, 1391 (2013).

[17] Н.И. Бочкарева, Ю.Т. Ребане, Ю.Г. Шретер. ФТП, 49, 1714 (2015).

[18] J. Iveland, L. Martinelly, J. Peretti, J.S. Speck, C. Weisbuch. Phys. Rev. Lett., 110, 177406 (2013).

[19] E.F. Schubert. Light-Emitting Diodes (Cambridge University Press, N.Y., 2003).

[20] В.В. Безотосный, В.Ю. Бондарев, О.Н. Крохин, В.А. Олещенко, В.Ф. Певцов, Ю.М. Попов, Е.А. Чешев. ФТП, 48, 114 (2014).

[21] Н.И. Бочкарева, А.А. Ефремов, Ю.Т. Ребане, Р.И. Горбунов, А.В. Клочков, Ю.Г. Шретер. ФТП, 40, 122 (2006).

Редактор А.Н. Смирнов

\section{Edge and defect luminescence of powerful InGaN / GaN ultraviolet light-emitting diodes}

\author{
V.T. Shamirzaev $\times$, V.F. Gaisler*×, T.S.Shamirzaev*+ \\ $\times$ Novosibirsk State Technical University, \\ 630073 Novosibirsk, Russia \\ * Rzhanov Institute of Semiconductor Physics \\ Siberian Branch of Russian Academy of Science, \\ 630090 Novosibirsk, Russia \\ + Ural Federal University, \\ 620002 Yekaterinburg, Russia
}

\begin{abstract}
The spectra of ultraviolet InGaN / GaN light-emitting diodes and its dependence on the current flowing through the structure have been studied. The intensity of the ultraviolet contribution to the integrated electroluminescence increases monotonically with increasing density of the current flowing through the structure, despite to the drop in quantum efficiency of radiation. The conditions for electroluminescence excitation, allowing increased ultraviolet radiation percentage up to $97 \%$ has been found. It is shown that the non-uniform generation of extended defects that penetrate the active region in the lightemitting diodes during local overheating reduces the integrated radiation intensity, but does no effect on the relative intensity of ultraviolet $(370 \mathrm{~nm})$ and visible $(550 \mathrm{~nm})$ radiation.
\end{abstract}

